\title{
Aggressive Systemic Mastocytosis
}

National Cancer Institute

\section{Source}

National Cancer Institute. Aggressive Systemic Mastocytosis. NCI Thesaurus. Code C9285.

An aggressive and progressive mast cell neoplasm characterized by systemic infiltration of internal organs by aggregates of neoplastic mast cells. There is no evidence of mast cell leukemia or clonal hematologic malignancy. Clinical symptoms include hepatomegaly, splenomegaly, portal hypertension, malabsorption syndrome, and pathologic fractures. 